\title{
Spatial Distributions of Carbon Storage and Uptake of Urban Forests in Seoul, South Korea
}

\author{
Do-Hyung Lee, ${ }^{1}$ Sung-Ho Kil, ${ }^{2 *}$ Hyun-Kil Jo, ${ }^{2}$ and Byoungkoo $\mathrm{Choi}^{3}$ \\ ${ }^{1}$ Green Business Division, Korea Research Institute on Climate Change, \\ Chuncheon 24239, South Korea \\ ${ }^{2}$ Department of Ecological Landscape Architecture Design, Kangwon National University, \\ Chuncheon 24341, South Korea \\ ${ }^{3}$ Department of Forest Environment Protection, Kangwon National University, \\ Chuncheon 24341, South Korea
}

(Received August 17, 2019; accepted October 23, 2019)

Keywords: climate change, ecosystem service, tree cover, vegetation index, forest management

Urban forests are crucial to alleviate climate change by reducing the amount of carbon dioxide $\left(\mathrm{CO}_{2}\right)$ in the atmosphere. Although recent research has mapped the ecosystem service worldwide, most studies have not obtained accurate results owing to the usage of high-cost and low-resolution data. Hence, herein, carbon storage and carbon uptake per capita are quantified and mapped for all administrative districts of the Seoul Metropolitan City through (1) the analysis of tree cover via on-site tree investigation and aerial imagery and (2) geographic information system (GIS) analysis, targeting the Seoul Metropolitan City of South Korea, which has achieved the highest level of development. Results indicate that the total carbon storage and carbon uptake of Seoul are approximately $1459024 \mathrm{t}$ and $147388 \mathrm{t} / \mathrm{yr}$, respectively; the corresponding per unit area values are approximately $24.03 \mathrm{t} / \mathrm{ha}$ and $2.43 \mathrm{t} / \mathrm{ha} / \mathrm{yr}$, which are lower than those of other cities. In particular, carbon storage and uptake per capita benefits of the urban areas, except for the urban forest areas, are confirmed to show a maximum difference $(\sim 20$ times) between the regions. This signifies a significant difference between areas in receiving carbon per capita benefits. Finally, we intend to quantify the tree cover and carbon cycle of urban areas of Seoul and map them in order to recognize areas requiring potential planting spaces. This will aid landscape planners and policy makers in establishing plans and policies for urban trees toward alleviating climate change and reducing the amount of fine dust and $\mathrm{CO}_{2}$ concentrations.

\section{Introduction}

Urban trees are uniquely capable of controlling carbon storage and emission in urban areas, ${ }^{(1,2)}$ and urban forests play a particularly important role in city areas with the highest carbon emissions, by affecting carbon circulation, reducing the amount of greenhouse gases, and alleviating climate change. ${ }^{(3-5)}$ However, their importance is not well recognized owing to the lack of understanding of their benefits. ${ }^{(6)}$ Urban forests also provide various ecosystem

*Corresponding author: e-mail: sunghokil@kangwon.ac.kr https://doi.org/10.18494/SAM.2019.2556 
services such as microclimate improvement, atmospheric cleanup, ${ }^{(7)}$ energy saving, ${ }^{(8)}$ rainwater collection and storage, the improvement of biological diversification, ${ }^{(9)}$ and the enhancement of soil fertilization; ${ }^{(10)}$ ecological benefits such as noise reduction, landscape beauty and amenity, and recreation and learning; ${ }^{(11)}$ esthetic/welfare benefits such as health improvement; ${ }^{(12)}$ and socioeconomic benefits such as real estate and property value increase. ${ }^{(13)}$

The ecosystem service that is extremely important for our lives is carbon storage and uptake by vegetation; this plays a particularly important role in the alleviation of climate change, the severity of which has been realized only in recent decades. ${ }^{(14,15)}$

Climate change has come to the fore as the most serious environmental issue globally. ${ }^{(16-18)}$ One of the major causes of climate change is the production of greenhouse gases and aerosols, which highly contaminate the atmosphere. In particular, the air in East Asian countries, such as Korea, China, and India, is loaded with fine dust particles and is one of the causes of atmospheric contamination, whereas East European countries, where various fossil fuels are mainly used as fuel, suffer greatly from atmospheric pollution. This environmental problem is now considered as a trans-global issue. In this regard, the Paris Climate Agreement was adopted to combat climate change, replacing the Kyoto Protocol, in the general assembly of concerned nations in Paris in 2015. Various measures were adopted, such as setting targets to not exceed a $2{ }^{\circ} \mathrm{C}$ rise above pre-industrial levels in the global temperature during this century. ${ }^{(19)}$

With the rapid increase in population in urban areas globally (the proportion is expected to reach almost $70 \%$ by 2050), urban planners and policy makers need to formulate plans and manage them systematically to achieve urban carbon emission reduction targets. ${ }^{(20,21)}$ To achieve this, the quantification and mapping of carbon storage and uptake quantities are crucial. $^{(22-24)}$

Considering relevant research over the past decade with keywords such as 'ecosystem mapping and modeling' and 'carbon', unit-based studies on the local, ${ }^{(25)}$ regional, ${ }^{(26,27)}$ national, ${ }^{(28-30)}$ and global ${ }^{(31)}$ levels using land use maps have been conducted. However, the land use maps were derived from remote sensing, which is characterized by the issue of spatial error. $^{(32,33)}$ There are also active studies utilizing satellites such as Landsat TM/ETM; ${ }^{(34-36)}$ however, data from Landsat images have lower credibility when employed in mapping because of low resolution $(30 \mathrm{~m})$. Moreover, cloud interference makes it difficult to obtain highquality visuals over a specific period of time. ${ }^{(37)}$ To overcome this, extensive research has been conducted utilizing field survey data or high-resolution visuals (i.e., QuickBird image and LiDAR). However, they have drawbacks such as high costs involved in data collection and spatial heterogeneity that results in mapping errors. ${ }^{(38)}$

The purpose of this research is to map an ecosystem service targeting urban units with the highest developmental achievements using aerial images; the study was conducted as follows:

(1) the analysis and comparison of tree cover of the target area using aerial images and field data,

(2) the analysis of carbon storage and uptake quantity of the target area by the registered land, and

(3) the analysis and mapping by the administrative district, including those of carbon storage and uptake per capita quantity. Finally, by recognizing areas with less benefits of carbon 
storage and uptake by administrative district and population, we intend to aid landscape planners and policy makers in realizing planning and policy making to not only increase the amount of flora and fauna, but also channel these efforts toward alleviating climate change and offsetting greenhouse emissions by region and population.

\section{Materials and Methods}

\subsection{Study area}

The main target area of this research is the Seoul Metropolitan City, the capital city of South Korea (longitude: 127.02 'E, latitude: 37.53 'N, and land area: $605 \mathrm{~km}^{2}$ ) (Fig. 1). Seoul is composed of 25 autonomous districts and 467 administrative towns, and the total population is approximately 976 million, which indicates a decreasing trend compared with the peak of 1016 million in the 1990s. ${ }^{(39)}$ Seoul is located geographically in the midwestern region of South Korea (Fig. 1); it is shaped like a basin and is surrounded by Bookhansan Mountain, Boolamsan Mountain, and Kwanaksan Mountain. The Han River runs from the west to the east, crossing the city center. The climate of Seoul ranges from warm to cold. There is a clear four-season difference, with significant differences in temperature and rainfall throughout the year. The average temperature per year is $12.2{ }^{\circ} \mathrm{C}$, with $25.3{ }^{\circ} \mathrm{C}$ in summer and $-5.0{ }^{\circ} \mathrm{C}$ in winter. The recorded annual average rainfall is $1646 \mathrm{~mm}$.

\subsection{Image data processing}

After acquiring the first historical aerial image in 1947, South Korea has been collecting aerial images once every two to three years, including location information since 2010. The National Geographical Information Institute provides the data free of charge, enabling this research to utilize 214 shots taken in 2014 and 2015 as data for analysis. Some of the images

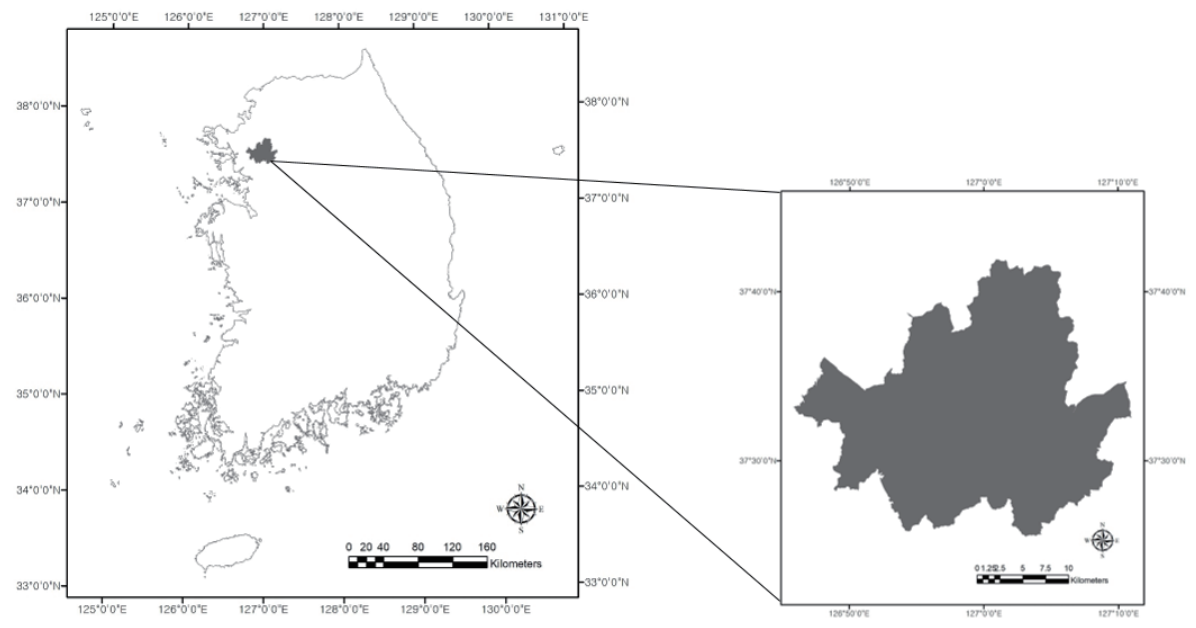

Fig. 1. Study site (Seoul, South Korea). 
taken in winter show snow cover even for a forested area; therefore, the 5th forest-type map of 1:5000 scale made in 2010 was used to determine the diameter and age class of forest stands including spatial arrangement of forest community and thus calculate the carbon storage and carbon uptake.

\subsection{Field data}

As for field data, in all, 14 site investigations of trees were carried out from June 27 until early August of 2017 by classifying the green spaces of Seoul into three categories of land use types: public institutions, apartments, and parks. To establish the point of the investigation, the stratified sampling method was used in accordance with previous research. Jo et al., ${ }^{(40)}$ Jo et al., ${ }^{(41)}$ and Jo et al. ${ }^{(42)}$ selected the center point of the study site in the aerial image of 1:1000 scale, and drew eight straight lines toward eight different directions and rings with $40 \mathrm{~cm}$ intervals to prepare a map in radial and ring patterns. Finally, by selecting the points where the eight straight lines cross the ring as samples, 90 samples were identified. For every investigation spot, vertical and horizontal sections were investigated for tree species, diameter at breast height $(\mathrm{DBH})$, tree height, crown width, and tree density. Trees were measured at a height of $1.2 \mathrm{~m}$ and shrubs at $15 \mathrm{~cm}$ from the ground.

\subsection{Calculating vegetation index using tree cover}

Thus far, there has been extensive research using spectral bands to calculate vegetation indices (VIs), such as Simple Ratio Index (SRI), ${ }^{(43)}$ Normalized Difference Vegetation Index $(\mathrm{NDVI}),{ }^{(44)}$ Enhanced Vegetation Index (EVI) ${ }^{(45)}$ Green Atmospherically Resistant Vegetation Index (GARVI), ${ }^{(4)}$ and Wide Dynamic Range Vegetation Index (WDRVI) ${ }^{(47)}$ However, the aerial images used in this research, as provided by the National Geographical Information Institute, only had the red, green, and blue (RGB) band; therefore, the research result of Meyer and Neto (2008) ${ }^{(48)}$ was used. Owing to the absence of near-infrared (NIR) values, in this research, we could only confirm the optimal VI by comparing various VI values using only the RGB values.

$$
R^{*}=\frac{R}{255}, G^{*}=\frac{G}{255}, B^{*}=\frac{B}{255}
$$

The RGB values here are the pixel values of each radiating corrected aerial image. First, the $R^{*}, G^{*}$, and $B^{*}$ values were generated by standardizing the $R, G$, and $B$ values between 0 and 1 using Eq. (1).

$$
r=\frac{R^{*}}{R^{*}+G^{*}+B^{*}}, g=\frac{G^{*}}{R^{*}+G^{*}+B^{*}}, b=\frac{B^{*}}{R^{*}+G^{*}+B^{*}}
$$

Subsequently, $r, g$, and $b$ values were calculated using Eq. (2). 


$$
\begin{gathered}
E x R=1.4 r-b \\
E x G=2 g-r-b
\end{gathered}
$$

$E x R$ and $E x G$ were calculated using Eqs. (3) and (4), respectively.

$$
V I=E x G-E x R
$$

Finally, using Eq. (5), VI was calculated, which ranged between -2.4 and 2, with a resolution of $1 \mathrm{~m} .^{(48)}$

\subsection{Regression analysis of tree cover}

The statistical analysis adopted the SPSS statistics (version 24) tool, with the on-site investigated tree cover as an independent variable and geographic information system (GIS)analyzed tree cover as a dependent variable. Regression analyses of 10 models (linear, logarithmic, inverse, quadratic, cubic, compound, S, logistic, growth, and exponential models) were carried out via linear and curve tracking analysis. Among the models, optimal models with a higher coefficient of determination and a significance probability of less than 0.05 were selected.

\subsection{Allometric equations of carbon storage and uptake}

For the biomass of individual trees, the allometric growth model developed in previous research was used. Thus far, most domestic and foreign research studies have used the growth models developed from the National Institute of Forest Science against forest areas in South Korea; however, as the environment of urban trees is different from its forest trees in terms of growth environment, ${ }^{(47-49)}$ in this research, we used the quantitative model developed against trees of the central areas of South Korea (Appendixes 1 and 2). ${ }^{(50-53,58)}$ For arbor trees with no quantitative models, the same family or group of equations was used, and a quantitative model for shrubs developed by Jo ${ }^{(54)}$ was used. The allometric equation calculated these values for the trees using a method developed with $\mathrm{DBH}$ or diameter at $15 \mathrm{~cm}$ above ground (DAG) as an independent variable.

\subsection{Calculation of carbon storage and uptake quantities of urban forest and urban areas}

Seoul comprises 25 "Gu's" and is a basin-shaped city surrounded by forests. Up in the north are located the Bookhansan and Dobongsan Mountains; at the center of Gangbuk (north of the river) are located the Naksan, Inwangsan, Namsan, and Bookaksan mountains, each at the east, west, south, and north, respectively; at the northeast are the Sooraksan and Boolamsan Mountains; and at the south are the Gwanaksan and Chonggyesan Mountains. There are also other small and medium-scale urban forests in various areas. However, as each "Gu" 
has a different population, areas occupied by urban forests, and different tree covers at urban areas, the calculation was performed for carbon storage and uptake per capita quantity for the urban forest and urban areas in each administrative district. The calculation methods for this are already described above, and the carbon storage and uptake per capita quantity by each administrative district were calculated by subtracting the carbon storage and uptake quantities of the urban forest area from the total carbon storage and uptake quantities, and by dividing these by the population of each administrative district (Fig. 2).

\section{Results}

\subsection{Tree cover}

The tree cover of Seoul is approximately $233 \mathrm{~km}^{2}$ and is particularly high in the forest areas surrounding the city center rather than the city center. The average tree cover of 967114 points for the total registered area was about $39.4 \%$. In the administrative district, the average covers were $10-20 \%$ ( 2 ea), $20-30 \%$ (6 ea), 30-40\% (9 ea), 40-50\% (1 ea), 50-60\% (3 ea), and 60-70\% (4 ea), as listed in Table 1 and Fig. 3.

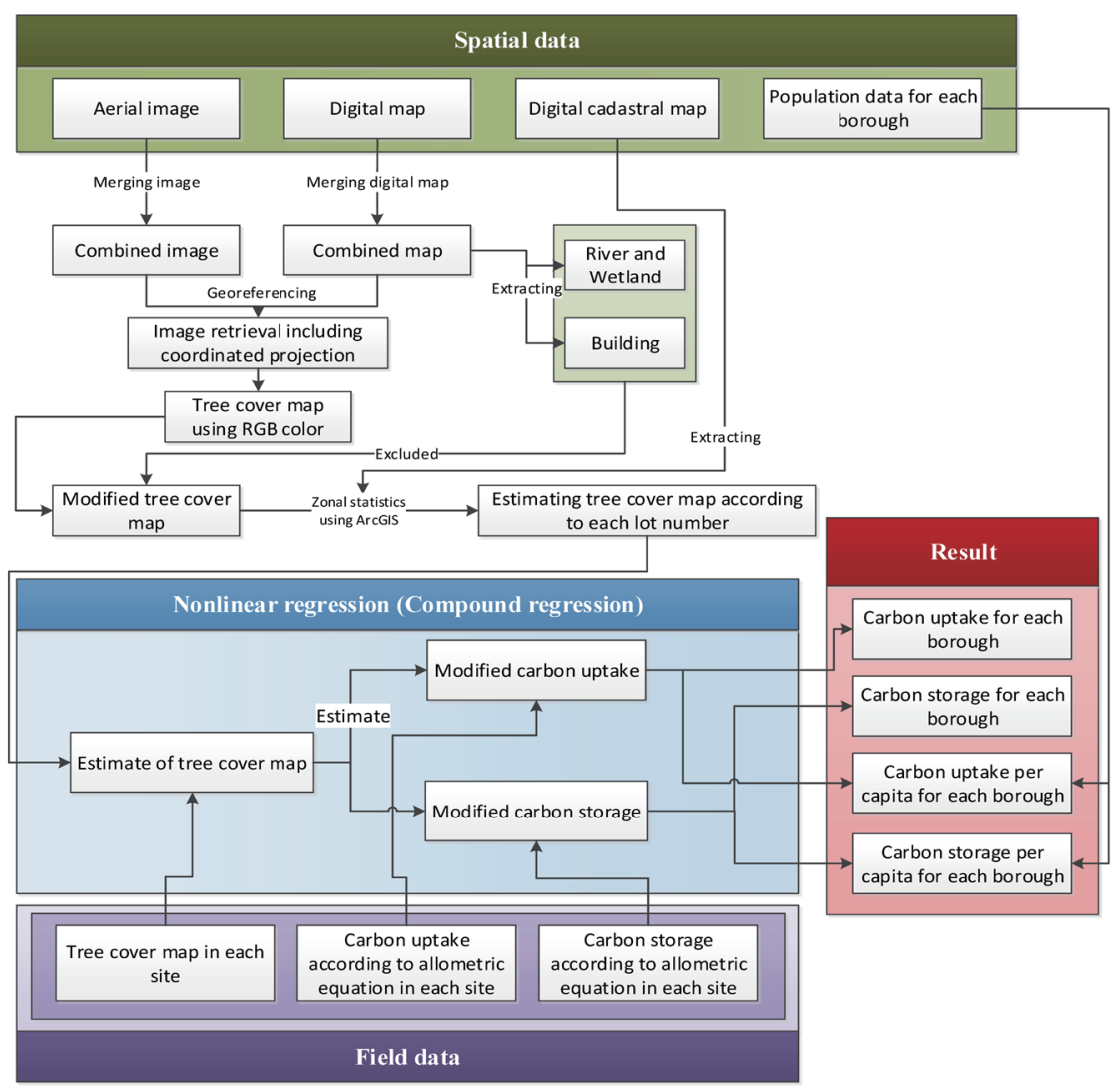

Fig. 2. (Color online) Flow chart depicting all aspects of the current study. 
Table 1

Tree cover in the administrative districts of Seoul.

\begin{tabular}{lclc}
\hline Borough & $\begin{array}{c}\text { Tree cover } \\
(\%)\end{array}$ & Borough & $\begin{array}{c}\text { Tree cover } \\
(\%)\end{array}$ \\
\hline Gangnam & 38.5 & Seodaemun & 49.4 \\
Gangdong & 10.1 & Seocho & 62.3 \\
Gangbuk & 60.6 & Seongdong & 20.1 \\
Gangseo & 20.6 & Seongbuk & 34.9 \\
Gwanak & 67.0 & Songpa & 31.4 \\
Gwangjin & 39.4 & Yangcheon & 34.0 \\
Guro & 32.0 & Yeongdengpo & 17.3 \\
Geumcheon & 38.0 & Yongsan & 20.1 \\
Nowon & 63.1 & Eunpyeong & 52.8 \\
Dobong & 59.4 & Jongno & 59.9 \\
Dongdaemun & 21.2 & Jung & 24.5 \\
Dongjak & 37.6 & Jungnang & 30.5 \\
Mapo & 22.1 & Total mean & 39.4 \\
\hline
\end{tabular}

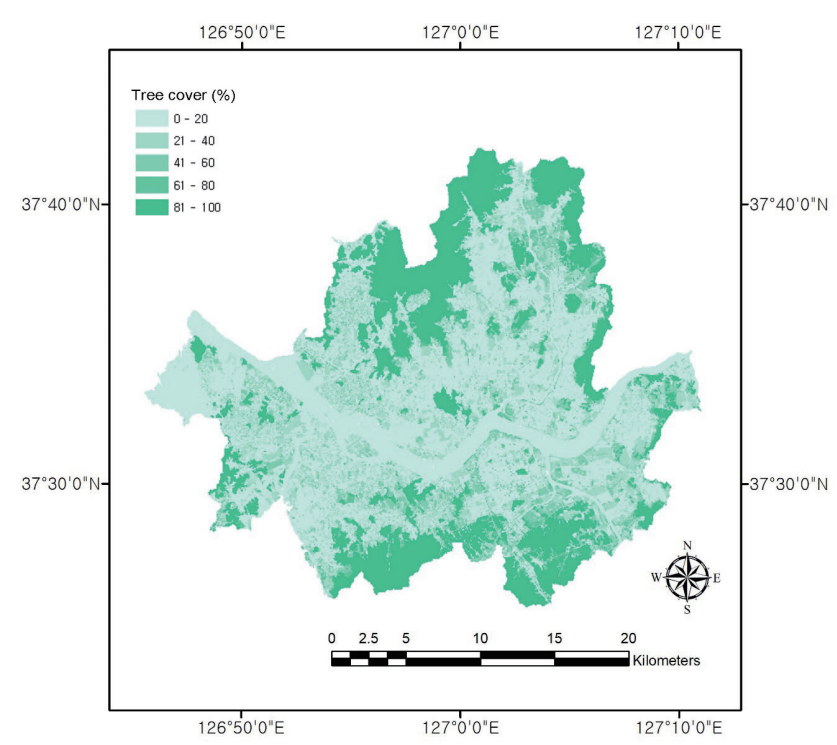

Fig. 3. (Color online) Tree cover map.

\subsection{Comparative analyses of VI analyzed with GIS within the city center using on-site investigation data}

In the comparison between the tree cover analyzed using GIS and that from the on-site investigation, the unclear data from the newly composed places or changes of institutions were excluded. Moreover, out of 90 plots under on-site investigation, 21 data considered as statistical outliers were excluded and a regression analysis was performed for the chosen 69 plots. As a result of this regression analysis, it was revealed that the involution model was appropriate for both the carbon storage and uptake quantities. This regression model was statistically significant after $\mathrm{F}$ verification $(p<0.01)$, and the goodness of fit was high with 0.95 and 0.96 of $r^{2}$.

\subsection{Mapping urban vegetation}

\subsubsection{Carbon storage and uptake quantities of the whole Seoul}

The carbon storage and uptake quantities of the whole Seoul, with tree cover as an independent variable, were approximately $1459024 \mathrm{t}$ and $147388 \mathrm{t} / \mathrm{yr}$, respectively. The average carbon storage and uptake per unit area were approximately $24.03 \mathrm{t} / \mathrm{ha}$ and $2.43 \mathrm{t} / \mathrm{ha} / \mathrm{yr}$, respectively (Figs. 4 and 5).

The highest average carbon storage and carbon uptake quantities in each registered land were revealed to originate from urban forests, and the order was park, apartment, and lands for public use. 


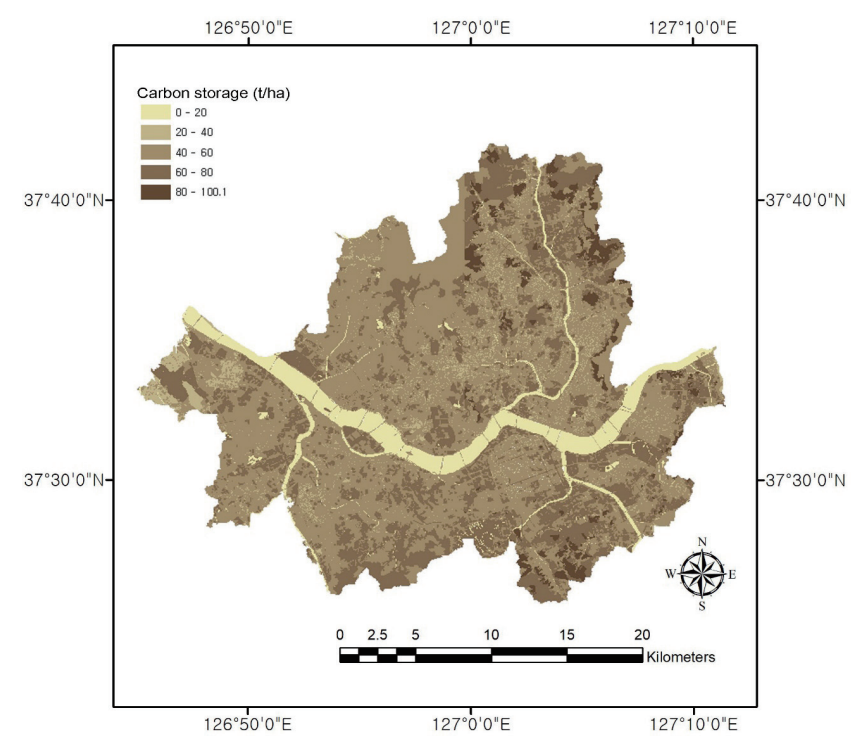

Fig. 4. (Color online) Carbon storage for the whole Seoul.

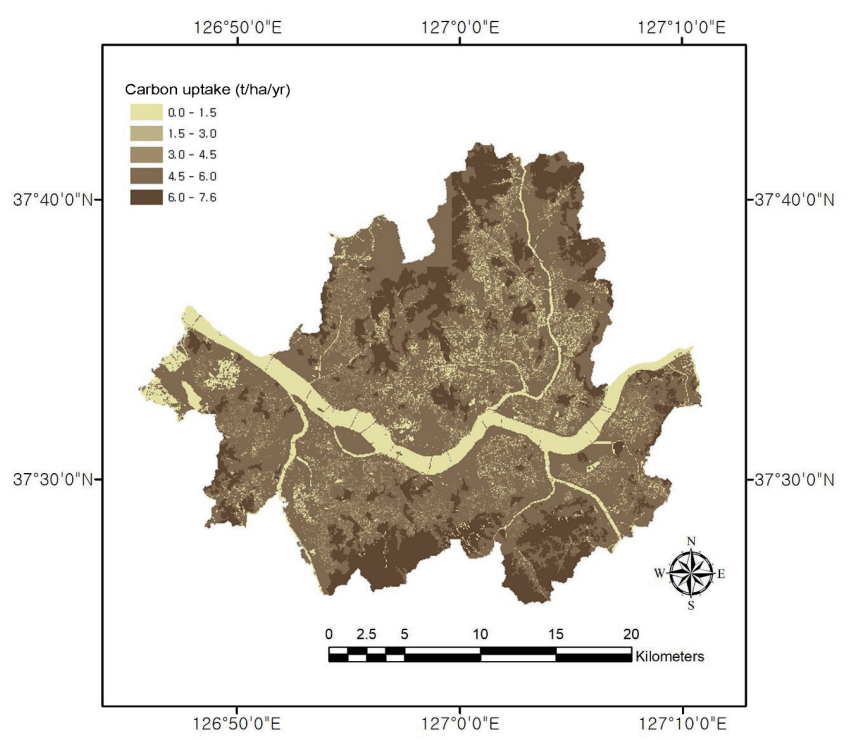

Fig. 5. (Color online) Carbon uptake for the whole Seoul.

\subsubsection{Carbon storage and uptake quantities in administrative districts}

The order of carbon storage quantity in the administrative districts was Gwanakgu (43.04 t/ha), Nowongu (42.7 t/ha), and Seochogu (41.29 t/ha), and the order of the carbon uptake quantity was Gwanakgu (4.53 t/ha/yr), Dobonggu (4.13 t/ha/yr), and Nowongu (4.08 $\mathrm{t} / \mathrm{ha} / \mathrm{yr}$ ). This is because there are wide areas of urban forests around Seochogu, Nowongu, and Gwanakgu producing such results. However, Mapogu, Seongdonggu, and Yeongdeungpogu showed the lowest carbon storage quantities of 9.91, 9.77, and $7.87 \mathrm{t} / \mathrm{ha}$, and the lowest carbon uptake quantities of $0.90,0.86$, and $0.68 \mathrm{t} / \mathrm{ha} / \mathrm{yr}$, respectively (Figs. 6 and 7). This is because there are relatively fewer urban forest areas within their administrative districts.

\subsubsection{Carbon storage and uptake quantities in urban forest areas}

The carbon storage quantity of the urban forest areas of Seoul was $63.19 \mathrm{t} / \mathrm{ha}$ and the carbon uptake quantity was $6.84 \mathrm{t} / \mathrm{ha} / \mathrm{yr}$, amounting to 63.8 and $68.5 \%$ of the total carbon storage and carbon uptake quantities, respectively, emphasizing the important roles played by the urban forest surrounding Seoul as a source of carbon storage and uptake (Figs. 8 and 9).

\subsubsection{Carbon storage and uptake quantities in urban areas}

The carbon storage and uptake quantities of urban areas, excluding the forest areas within the city, were $11.42 \mathrm{t} / \mathrm{ha}$, and $1.00 \mathrm{t} / \mathrm{ha} / \mathrm{yr}$, which are 36.2 and $31.5 \%$ of the total carbon storage and carbon uptake quantities, respectively. Yeongdeungpogu, Seongdonggu, and Mapogu 


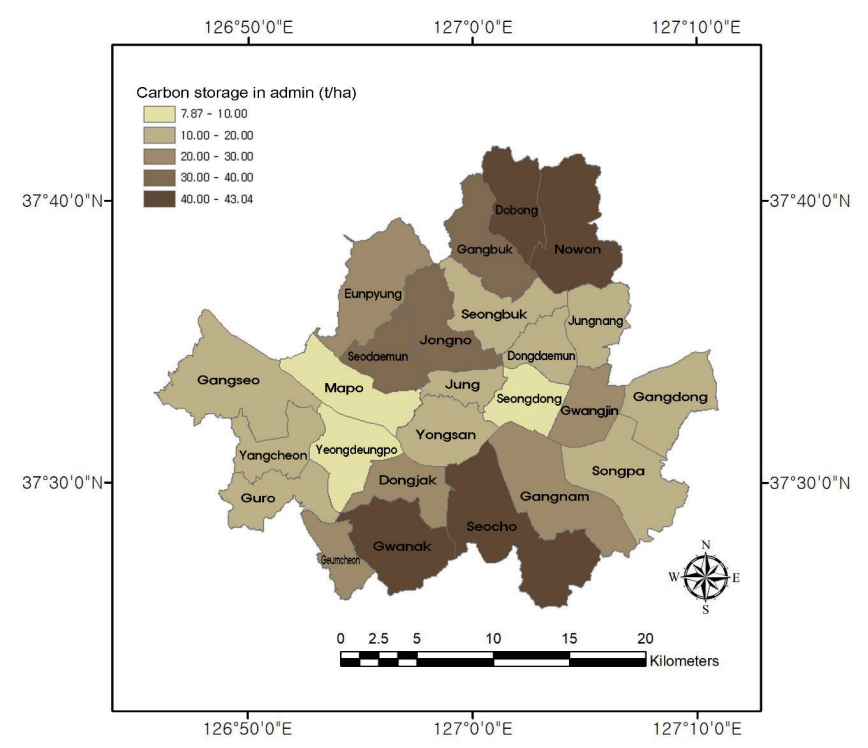

Fig. 6. (Color online) Carbon storage in administrative districts.

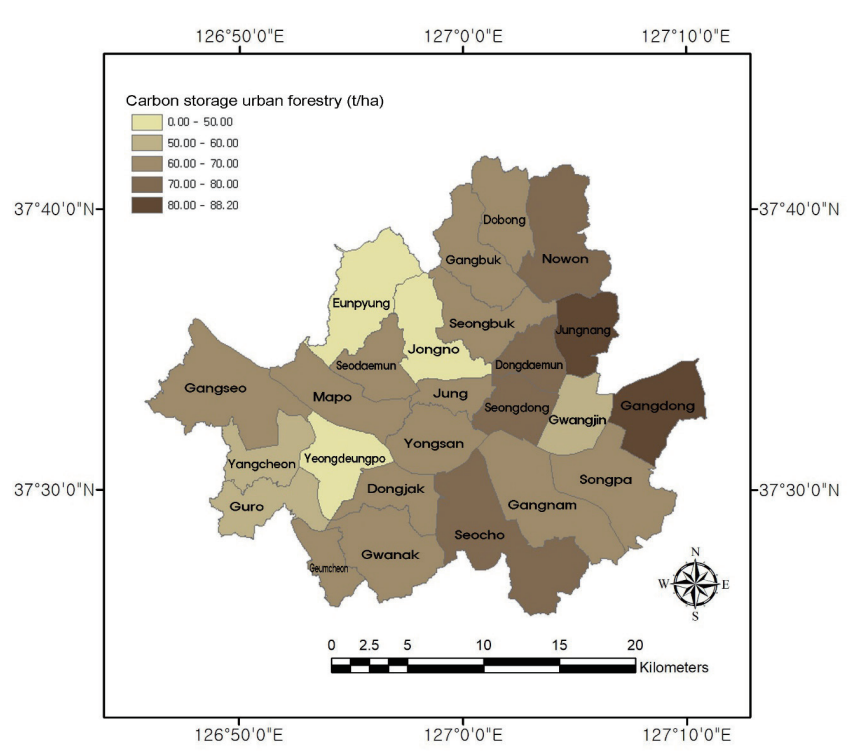

Fig. 8. (Color online) Carbon storage in urban forest areas.

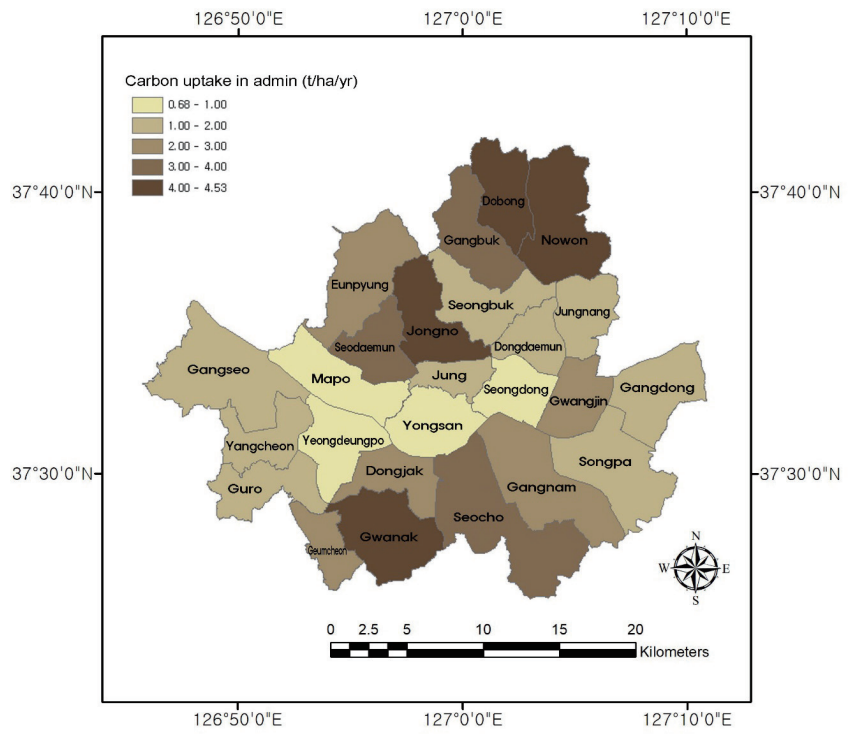

Fig. 7. (Color online) Carbon uptake in administrative districts.

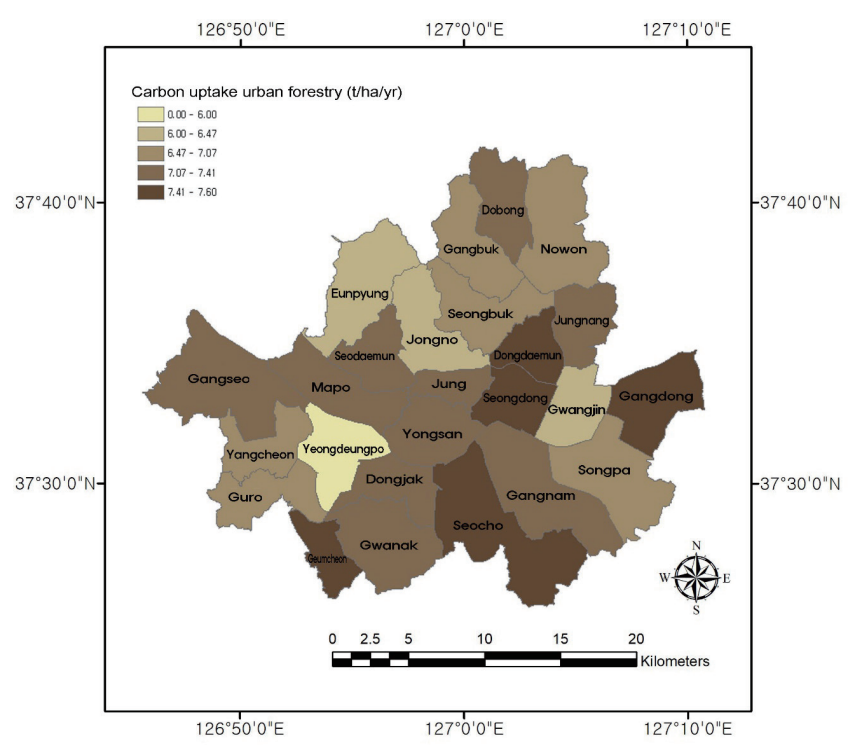

Fig. 9. (Color online) Carbon uptake in urban forest areas.

showed the lowest total carbon storage and uptake quantities (Figs. 10 and 11). This means that the trees in urban areas play an important role in these regions. On the other hand, the total carbon storage and uptake percentages of Gangbukgu, Dobonggu, and Jongnogu among the 25 "Gu"s excluding the forest areas within the city were in the lower range (between 8 and 20\%), requiring green infrastructure and plant planning in these urban areas. 


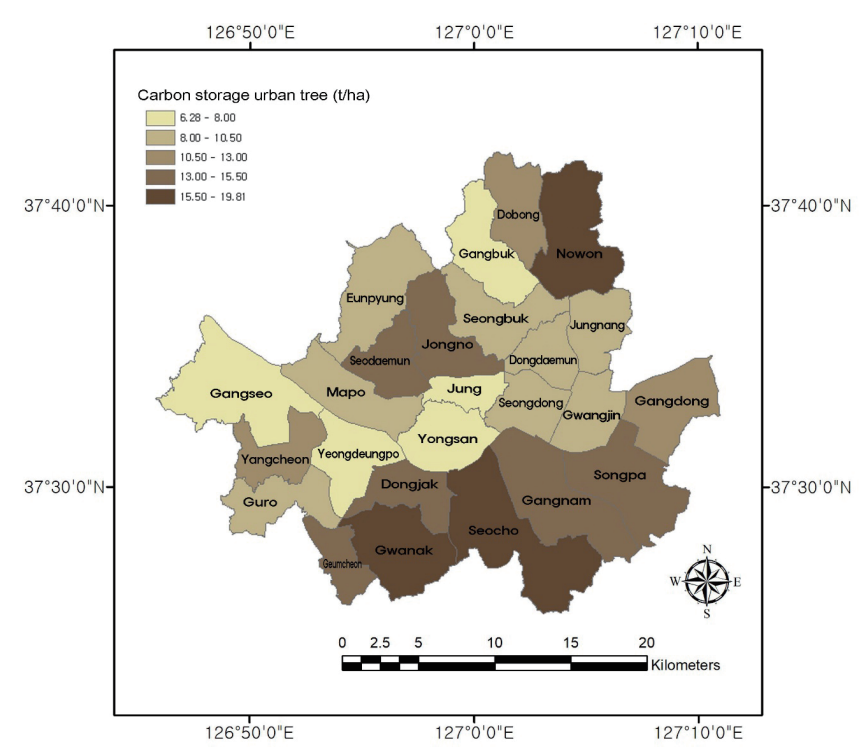

Fig. 10. (Color online) Carbon storage in urban areas.

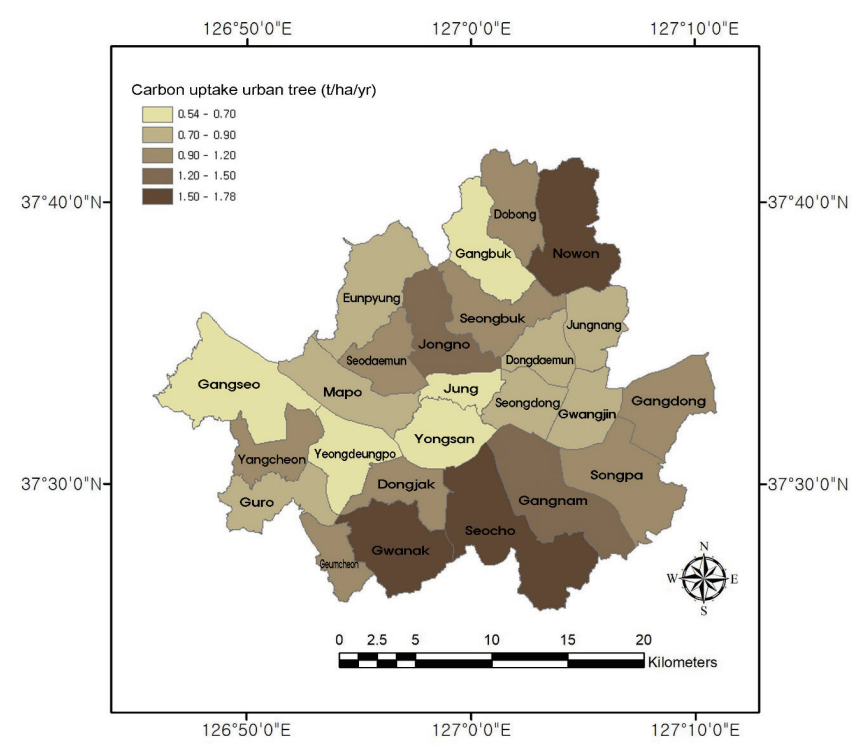

Fig. 11. (Color online) Carbon uptake in urban areas.

\subsubsection{Carbon storage and uptake per capita quantities in administrative districts}

When calculating the carbon storage and uptake per capita quantities in the administrative districts based on the total carbon storage and uptake quantities and the population of each "Gu", the order of carbon storage quantity in Seoul was Jongnogu ( $0.51 \mathrm{t} / \mathrm{per})$, Seochogu $(0.45 \mathrm{t} / \mathrm{per})$, and Nowongu ( $0.27 \mathrm{t} / \mathrm{per})$, and the order of carbon uptake quantity was Jongnogu ( $0.06 \mathrm{t} / \mathrm{per} / \mathrm{yr})$, Seochogu (0.04 t/per/yr), and Gangbukgu (0.03 t/per/yr) as listed in Table 2 and Figs. 12 and 13. These regions include urban forest areas showing relatively higher total carbon storage and uptake quantities.

\section{Discussion}

In this research, we calculated and mapped the carbon storage and uptake quantities to propose urban green space management and planning measures targeting public institutions, apartments, and parks in Seoul. Although one of the biggest cities in the world, Seoul has a small area but a large population density of $17473 / \mathrm{km}^{2}$, which is the second highest after Beijing when compared with other cities such as London, New York, Singapore, and Tokyo. Accordingly, the carbon dioxide $\left(\mathrm{CO}_{2}\right)$ emission in air is high and measures are required to reduce and offset such emission; however, because the existing studies have been performed only by sampling two "Gu"s for carbon storage and uptake quantities and the quantitative analysis towards the whole city was nonexistent, this research is considered to be of significance in this regard.

The total tree cover of Seoul is about 39.4\%, which is relatively higher than those of other cities; however, the urban area tree cover excluding the urban forests surrounding the city was 
Table 2

Population, carbon storage quantity, and carbon uptake quantity in administrative districts.

\begin{tabular}{|c|c|c|c|c|c|c|c|}
\hline Borough & Population & $\begin{array}{c}\text { C storage } \\
\text { (t/per) }\end{array}$ & $\begin{array}{l}\text { C uptake } \\
\text { (t/per/yr) }\end{array}$ & Borough & Population & $\begin{array}{c}\text { C storage } \\
\text { (t/per) }\end{array}$ & $\begin{array}{l}\text { C uptake } \\
\text { (t/per/yr) }\end{array}$ \\
\hline Gangnam & 556164 & 0.16 & 0.02 & Seodaemun & 312800 & 0.19 & 0.02 \\
\hline Gangdong & 436223 & 0.11 & 0.01 & Seocho & 441102 & 0.45 & 0.04 \\
\hline Gangbuk & 324479 & 0.26 & 0.03 & Seongdong & 304808 & 0.05 & 0.00 \\
\hline Gangseo & 601691 & 0.08 & 0.01 & Seongbuk & 444055 & 0.10 & 0.01 \\
\hline Gwanak & 503297 & 0.26 & 0.03 & Songpa & 664496 & 0.08 & 0.01 \\
\hline Gwangjin & 357703 & 0.10 & 0.01 & Yangcheon & 471154 & 0.07 & 0.01 \\
\hline Guro & 410742 & 0.08 & 0.01 & Yeongdengpo & 368550 & 0.05 & 0.00 \\
\hline Geumcheon & 235154 & 0.12 & 0.01 & Yongsan & 229161 & 0.09 & 0.01 \\
\hline Nowon & 554403 & 0.27 & 0.03 & Eunpyeong & 486794 & 0.14 & 0.02 \\
\hline Dobong & 344166 & 0.25 & 0.02 & Jongno & 154770 & 0.51 & 0.06 \\
\hline Dongdaemun & 350647 & 0.05 & 0.00 & Jung & 125709 & 0.13 & 0.01 \\
\hline Dongjak & 396217 & 0.10 & 0.01 & Jungnang & 408226 & 0.09 & 0.02 \\
\hline Mapo & 374915 & 0.07 & 0.01 & Average & 394297 & 0.15 & 0.02 \\
\hline
\end{tabular}

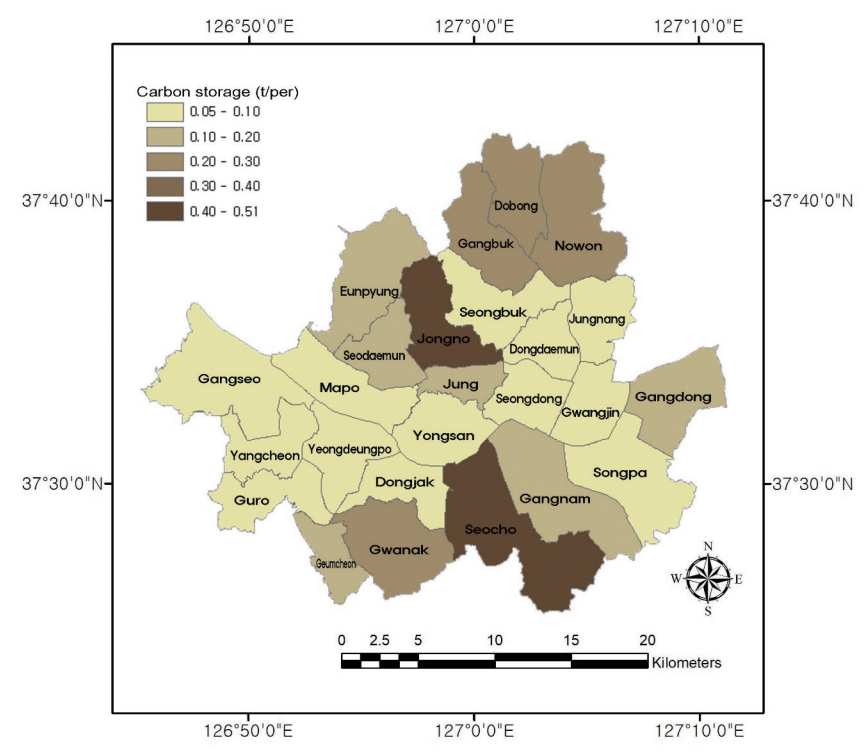

Fig. 12. (Color online) Carbon storage per capita quantities in administrative districts.

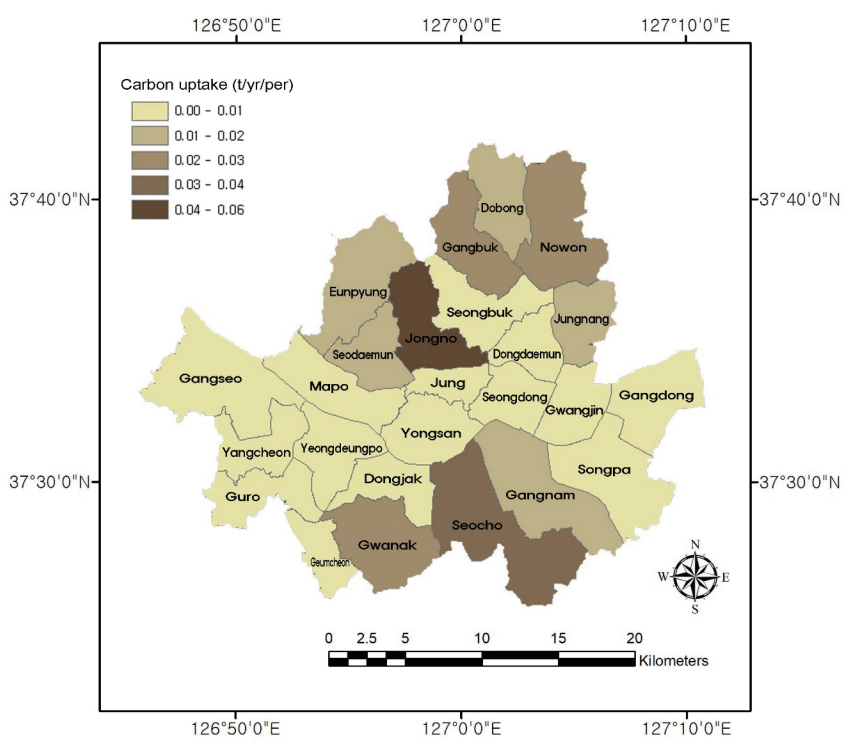

Fig. 13. (Color online) Carbon uptake per capita quantities in administrative districts.

only $14.7 \%$. This was not a significant difference from the $12-13 \%$ of Seoul's Jungnanggu and Gangnamgu's tree covers, according to a report by Jo. ${ }^{(55)}$ Compared with studies conducted in US cities with the highest tree cover, Atlanta (36.7\%), Boston (22.3\%), and Oakland (21\%) all recorded higher figures than Seoul. Even the UK's Leicester $(19 \%)^{(22)}$ and China's Xiamen $(46 \%)^{(55)}$ and Shenyang $(22.3 \%)^{(17)}$ reported higher figures.

Seoul's per ha carbon storage quantity is $24.03 \mathrm{t} / \mathrm{ha}$, which is apparently lower than those of cities such as Atlanta (35.74 t/ha), Baltimore (25.28 t/ha), ${ }^{(1)}$ and Beijing (43.70 t/ha). ${ }^{(56)}$ This is because, first, the street trees were excluded from the data analyzed and, second, Seoul has a lower density of trees planted, a small tree size, and an adverse growth environment. 
The carbon uptake quantity showed similar trends to the carbon storage quantity (Atlanta: $3.36 \mathrm{t} / \mathrm{ha} / \mathrm{yr}$, Baltimore: $3.34 \mathrm{t} / \mathrm{ha} / \mathrm{yr}$, and Washington DC: $3.23 \mathrm{t} / \mathrm{ha} / \mathrm{yr}){ }^{(1,57)}{ }^{2}$ however, the carbon uptake quantities of Seoul's Jungnanggu and Gangnamgu reported in the past research were 1.69 and $1.11 \mathrm{t} / \mathrm{ha} / \mathrm{yr}$, respectively, which were increased to $2.43 \mathrm{t} / \mathrm{ha} / \mathrm{yr}$ in this research, showing an increase in urban vegetation.

The total tree cover, carbon storage, and uptake show an increase in the amount of green space compared with that in the past. However, because the difference among the administrative districts is significant, and the areas with higher population densities and smaller green spaces cannot significantly benefit from the green spaces, considerable improvement is necessary in this regard. In particular, because the urban forests are not directly visited by people despite their relative proximity to the city and their actual benefits could not be effectively reaped, the expansion of green spaces within the city center has increased.

\section{Conclusions}

In this study, targeting the capital city of South Korea, Seoul, which has undergone significant development and has a high population density, we performed the quantitative analysis and mapping of carbon storage and uptake using on-site investigation data and by aerial imaging and mapping of forest types. The main conclusions are as follows: (1) The total tree cover of Seoul is about $39.4 \%$, which is relatively higher than those of other cities. (2) Total carbon storage and uptake quantities were confirmed to be favorable, with the carbon storage quantity being $1459024 \mathrm{t}$ and the carbon uptake quantity being $147388 \mathrm{t} / \mathrm{ha} / \mathrm{yr}$. (3) However, the carbon storage quantity of Seoul's urban forest area was $63.19 \mathrm{t} / \mathrm{ha}$ and the carbon uptake quantity was $6.84 \mathrm{t} / \mathrm{ha} / \mathrm{yr}$, amounting to 63.8 and $68.5 \%$ of the total carbon storage and uptake quantities, respectively. Moreover, the carbon storage and uptake quantities of urban areas were $11.42 \mathrm{t} / \mathrm{ha}$ and $1.00 \mathrm{t} / \mathrm{ha} / \mathrm{yr}$, amounting to 36.2 and $31.5 \%$ of the total carbon storage and uptake quantities, respectively, which were significantly less than those of urban forests. (4) Differences among the maximal and minimal administrative districts in terms of carbon storage and uptake quantities were more than 10 times, and the differences in carbon storage and uptake per capita quantities in the maximal administrative districts were more than 20 times, depicting significant regional differences. In fact, these regions are considered to not benefit much owing to the large transient population in addition to the resident population; however, this research was not able to address this point. In future studies, we aim to obtain a more accurate per capita benefit.

An on-site investigation on public institutions, apartments, and urban parks was performed, excluding the data for other green spaces such as street trees of the city and private lands. However, in an environment where no research on domestic ecosystem mapping has been performed, it is of significance to carry out this type of research. The result of this research may emphasize the importance of urban forests to alleviate climate change and will assist in the planning and development of urban forests and the selection and planting of urban trees for a decision making process using data of carbon storage and uptake of each registered land in Seoul in the future. 


\section{Acknowledgments}

This study was carried out with the support of the 'R\&D Program for Forest Science Technology (Project No. 2017043B10-1919-BB01)’ provided by the Korea Forest Service (Korea Forestry Promotion Institute).

\section{References}

1 D. J. Nowak, E. J. Greenfield, R. E. Hoehn, and E. Lapoint: Environ. Pollut. 178 (2013) 229. https://doi. org/10.1016/j.envpol.2013.03.019

2 J. Lee, G. Lee, and J. Kim: Forest Sci. Technol. 10 (2014) 80. https://doi.org/10.1080/21580103.2013.846876

3 E. G. McPherson, J. Simpson, P. Peper, and Q. Xiao: J. Arboric. 25 (1999) 235.

4 L. Gratani and L. Varone: Urban Ecosyst. 9 (2006) 27. https://doi.org/10.1007/s11252-006-5527-2

5 G. G. Lee, H. W. Lee, and J. H. Lee: Landscape Urban Plan. 140 (2015) 1. https://doi.org/10.1016/ j.landurbplan.2015.03.012

6 D. J. Nowak, E. J. Greenfield, R. E. Hoehn, and E. Lapoint: Environ. Pollut. 178 (2013) 229. https://doi. org/10.1016/j.envpol.2013.03.019

7 L. Yang, L. Zhang, Y. Li, and S. Wu: Landscape Urban Plan. 136 (2015) 40. https://doi.org/10.1016/ j.landurbplan.2014.11.016

8 C. Fan, S. W. Myint, and B. Zheng: Prog. Phys. Geogr. 39 (2015) 199. https://doi.org/10.1177/0309133314567583

9 M. W. Strohbach, S. B. Lerman, and P. S. Warren: Landscape Urban Plan. 114 (2013) 69. https://doi. org/10.1016/j.landurbplan.2013.02.007

10 J. L. Edmondson, Z. G. Davies, S. A. McCormack, K. J. Gaston, and J. R. Leake: Sci. Total Environ. 472 (2014) 444. https://doi.org/10.1016/j.scitotenv.2013.11.025

11 C. I. Iojă, S. R. Grădinaru, D. A. Onose, G. O. Vânău, and A. C. Tudor: Urban For. Urban Green. 13 (2014) 704. https://doi.org/10.1016/j.ufug.2014.07.002

12 J. Langemeyer, F. Baró, P. Roebeling, and E. Gómez-Baggethun: Ecosyst. Serv. 12 (2015) 178. https://doi. org/10.1016/j.ecoser.2014.11.016

13 S. K. Hong, J. M. Kim, H. K. Jo, and S. W. Lee: Sustainability 10 (2018) 1. https://doi.org/10.3390/su10072461

14 N. B. Grimm, S. H. Faeth, N. E. Golubiewski, C. L. Redman, J. Wu, X. Bai, and J. M. Briggs: Science 319 (2008) 756. https://doi.org/10.1126/science.1150195

15 Z. G. Davies, M. Dallimer, J. L. Edmondson, J. R. Leake, and K. J. Gaston: Environ. Pollut. 183 (2013) 133. https://doi.org/10.1016/j.envpol.2013.06.005

16 C. Rice, D. Gwary, H. Janzen, F. O’Mara, Z. Cai, S. Ogle S, B. Scholes, V. Romanenkov, T. McAllister, S. Towprayoon, M. Wattenbach, and J. Smith: Philos. Trans. R. Soc. B Biol. Sci. 363 (2007) 789. https://doi. org/10.1098/rstb.2007.2184.

17 C. Liu and X. Li: Urban For. Urban Green. 11 (2012) 121. https://doi.org/10.1016/j.ufug.2011.03.002

18 H. Jo and T. Ahn: J. Environ. Sci. Int. 22 (2013) 139. https://doi.org/10.5322/JESI.2013.22.2.139

19 P. González-Díaz, P. Ruiz-Benito, J. G. Ruiz, G. Chamorro, and M. A. Zavala: Sustainability 11 (2019) 358. https://doi.org/10.3390/su11020358

20 R. Hansen, N. Frantzeskaki, T. McPhearson, E. Rall, N. Kabisch, A. Kaczorowska, J. H. Kain, M. Artmann, and S. Pauleit: Ecosyst. Serv. 12 (2015) 228. https://doi.org/10.1016/j.ecoser.2014.11.013

21 G. Pulighe, F. Fava, and F. Lupia: Ecosyst. Serv. 22 (2016) 1. https://doi.org/10.1016/j.ecoser.2016.09.004

22 Z. G. Davies, J. L. Edmondson, A. Heinemeyer, J. R. Leake, and K. J. Gaston: J. Appl. Ecol. 44 (2011) 1125. https://doi.org/10.1111/j.1365-2664.2011.02021.x

23 N. D. Crossman, B. Burkhard, S. Nedkov, L. Willemen, K. Petz, I. Palomo, E. G. Drakou, B. Martín-Lopez, T. McPhearson, K. Boyanova, R. Alkemade, B. Egoh, M. B. Dunbar, and J. Maes: Ecosyst. Serv. 4 (2013) 4. https://doi.org/10.1016/j.ecoser.2013.02.001

24 N. Nikodinoska, E. Buonocore, A. Paletto, and P. P. Franzese: Appl. Energ. 186 (2017) 197. https://doi. org/10.1016/j.apenergy.2016.04.073

25 J. R. A. Butler, G. Y. Wong, D. J. Metcalfe, M. Honzák, P. L. Pert, N. Rao, M. E. V. Grieken, T. Lawson, C. Bruce, F. J. Kroon, and J. E. Brodie: Agr. Ecosyst. Environ. 180 (2013) 176. https://doi.org/10.1016/j.agee.2011.08.017

26 A. E. Ausseil, J. R. Dymond, M. U. F. Kirschbaum, and R. M. Andrew: Environ. Modell. Software 43 (2013) 37. https://doi.org/10.1016/j.envsoft.2013.01.006

27 B. A. Bryan and N. D. Crossman: Ecosyst. Serv. 4 (2013) 60. https://doi.org/10.1016/j.ecoser.2013.03.004 
28 I. J. Bateman, A. R. Harwood, G. M. Mace, R. T. Watson, D. J. Abson, B. Andrews, A. Binner, A. Crowe, B. H. Day, S. Dugdale, C. Fezzi, J. Foden, D. Hadley, R. Hanies-Young, M. Hulme, A. Kontoleon, A. A. Lovett, P. Munday, U. Pascual, J. Paterson, G. Perino, A. Sen, G. Siriwardena, D. V. Soest, and M. Termansen: Science 341 (2013) 45. https://doi.org/10.1126/science.1234379

29 B. A. Bryan, D. King, and G. Zhao: Environ. Res. Lett. 9 (2014) 04005. https://doi.org/10.1088/17489326/9/4/044005

30 J. Pasher, M. McGovern, M. Khoury, and J. Duffe: Urban For. Urban Green. 13 (2014) 484. https://doi. org/10.1016/j.ufug.2014.05.001

31 R. Costanza, R. d'Arge, R. De. Groot, S. Farberll, M. Grassot, B. Hannon, K. Limburg, S. Naeem, R. V. O. Neilltt, J. Paruelo, R. G. Raskin, P. Sutton, and M. V. D. Belt: Nature 387 (1997) 253. https://doi.org/10.1038/387253a0

32 S. Fritz, S. Linda, and F. Rembold: Int. J. Remote Sens. 31 (2010) 2237. https://10.1080/01431160902946598

33 M. Dong, B. A. Bryan, J. D. Connor, M. Nolan, and L. Gao: Ecosyst. Serv. 15 (2015) 63. https://doi.org/10.1016/ j.ecoser.2015.07.006

34 S. Myeong, D. J. Nowak, and M. J. Duggin: Remote Sens. Environ. 101 (2006) 277. https://doi.org/10.1016/ j.rse.2005.12.001

35 J. Jung, S. Kim, S. Hong, K. Kim, E. Kim, J. Im, and J. Heo: ISPRS J. Photogramm. Remote Sens. 81 (2013) 82. https://doi.org/10.1016/j.isprsjprs.2013.04.008

36 Y. Tao, F. Li, X. Liu, D. Zhao, X. Sun, and L. Xu: Ecol. Modell. 318 (2015) 210. https://doi.org/10.1016/ j.ecolmodel.2015.04.027

37 S. M. Raciti, L. R. Hutyra, and J. D. Newell: Sci. Total Environ. 500 (2014) 72. https://doi.org/10.1016/ j.scitotenv.2014.08.070.

38 C. Zhao and H. A. Sander: Landscape Urban Plan. 175 (2018) 11. https://doi.org/10.1016/j.landurbplan.2018.03.007

39 Seoul Institute. 2013 The Seoul Research Data Service. Available online: http://data.si.re.kr/node/56/ (accessed on 11 February 2019).

40 H. K. Jo, J. Y. Kim, and H. M. Park: JFES 34 (2018) 162. https://doi.org/10.7747/JFES.2018.34.2.162

41 H. K. Jo, J. Y. Kim, and H. M. Park: Urban For. Urban Green 41 (2019) 42. https://doi.org/10.1016/ j.ufug.2019.03.009

42 H. K. Jo, H. M. Park, and J. Y. Kim: Sustainability 11 (2019) 3543. https://doi.org/10.3390/su11133543

43 C. F. Jordan: Ecology 50 (1969) 663. https:// doi: 10.2307/1936256

44 J. W. Rouse, Jr., R. H. Haas, D. W. Deering, J. A. Schell, and J. C. Harlan: 3rd ERTS Symp. 1 (1974) 309.

45 A. R. Huete, H. Q. Liu, K. V. Batchily, and W. J. D. A. Van Leeuwen: Remote Sens. Environ. 59 (1997) 443. https://doi.org/10.1016/S0034-4257(96)00112-5

46 A. A. Gitelson, Y. J. Kaufman, and M. N. Merzlyak: Remote Sens. Environ. 58 (1996) 289. https://doi. org/10.1016/S0034-4257(96)00072-7

47 A. A. Gitelson: J. Plant Physiol. 161 (2004) 165. https://doi.org/10.1078/0176-1617-01176

48 G. E. Meyer and J. C. Neto: Comput. Electon. Agr. 63 (2008) 282. https://doi.org/10.1016/j.compag.2008.03.009

49 H. K Jo and T. W. Ahn: J. Korean Inst. Landsc. Archit. 40 (2012) 160. https://doi.org/10.9715/ KILA.2012.40.5.160

50 H. K. Jo and D. H Cho: J. Korean Inst. Landsc. Archit. 26 (1998) 38.

51 H. K. Jo and T. W. Ahn: Korean J. Env. Eco. 15 (2001) 118.

52 H. K. Jo and T. W. Ahn: J. Korean Inst. Landsc. Archit. 40 (2012) 160. https://doi.org/10.9715/ KILA.2019.47.3.031

53 H. K. Jo, J. Y. Kim, and H. M. Park: Korean J. Env. Eco. 27 (2013) 571. https://doi.org/10.13047/ KJEE.2013.27.5.571

54 H. K. Jo: J. Environ. Manage. 64 (2002) 115. https://doi.org/10.1006/jema.2001.0491

55 Y. Ren, X. Wei, X. Wei, J. Pan, P. Xie, X. Song, D. Peng, and J. Zhao: For. Ecol. Mana. 261 (2011) 1214. https:// doi.org/10.1016/j.foreco.2010.12.038

56 J. Yang, J. McBride, J. Zhou, and Z. Sun: Urban For. Urban Green. 3 (2004) 65. https://doi.org/10.1016/ j.ufug.2004.09.001

57 D. J. Nowak, R. E. Hoehn III, D. E. Crane, J. C. Stevens, and J. T. Walton: Resour. Bull. (2006) https://doi. org/10.2737/NRS-RB-1

58 H. K. Jo, J. Y. Kim, and H. M. Park: J. Korean Inst. Landsc. Archit. 42 (2014) 1. 


\section{About the Authors}

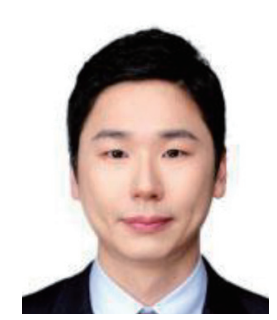

Do-Hyung Lee received his B.S. degree from Kangwon National University, South Korea in 2019. He has been a research scientist at Green Business Division, Korea Research Institute on Climate Change. His research interests include environmental planning and ecological investigation using remote sensing of satellite images and unmanned aerial vehicle (UAV) images.

(dhl@kric.re.kr)

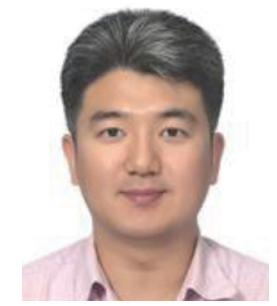

Sung-Ho Kil is an assistant professor at Kangwon National University. He graduated from Kangwon National University in 2003, majoring in landscape architecture. He earned his MLA and Ph.D. degrees from Seoul National University in 2007 and 2014, respectively. His research interests include ecological restoration, spatial ecology, and landscape ecology.

(sunghokil@kangwon.ac.kr)

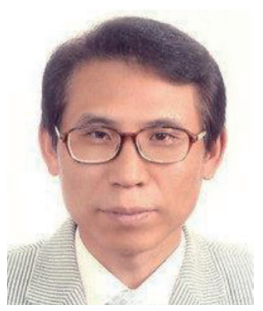

Hyun-Kil Jo is a professor in the Department of Ecological Landscape Architecture Design at Kangwon National University. He received B.S. and M.S. degrees from Kangwon National University and Seoul National University, Republic of Korea in 1982 and 1986, respectively, and his Ph.D. degree from the University of Arizona, USA in 1993. His research interests include ecological landscape, urban ecosystem and greenspace design, and carbon reduction of urban trees. (jhk@kangwon.ac.kr)

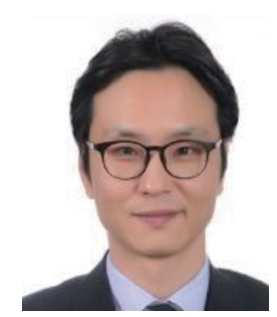

Byoungkoo Choi received his B.S. and M.S. degrees from Kangwon National University, Republic of Korea, in 2002 and 2004, respectively, and his Ph.D. degree from Mississippi State University, USA, in 2011. From 2014 to 2015, he was a research scientist at the National Institute of Ecology, Republic of Korea. Since 2015, he has been an assistant professor at Kangwon National University. His research interests include eco-hydrology, watershed management, and forestry BMPs. (bkchoi@kangwon.ac.kr) 


\section{Appendix 1}

Carbon storage allometric equation model for urban trees.

\begin{tabular}{|c|c|c|c|c|}
\hline \multicolumn{2}{|c|}{ Species } & Diameter range $(\mathrm{cm})$ & Allometric equations model & Reference \\
\hline \multirow{7}{*}{$\mathrm{BL}$} & Acer palmatum & $5-20$ & $Y=-23.2064+4.8538 \mathrm{DBH}$ & [52] \\
\hline & Chionanthus retusus & $3-11$ & $\ln Y=-2.7512+2.4952 \ln D B H$ & [58] \\
\hline & Cornus officinalis & $3-15$ & $\ln Y=-3.3110+2.4057 \ln D A G$ & [58] \\
\hline & Prunus armeniaca & $4-14$ & $\ln Y=-2.4307+2.2999 \ln D B H$ & [58] \\
\hline & Prunus yedoensis & $5-23$ & $\ln Y=-2.8265+2.4181 \ln D B H$ & [58] \\
\hline & Ginkgo biloba & $5-25$ & $\ln Y=-2.8428+2.3787 \ln D B H$ & [52] \\
\hline & Zelkova serrata & $5-28$ & $\ln Y=-2.4708+2.3862 \ln D B H$ & [52] \\
\hline \multirow{4}{*}{$\mathrm{CT}$} & Abies holophylla & $5-19$ & $\ln Y=-2.2126+2.0814 \ln D B H$ & [58] \\
\hline & Pinus densiflora & $5-25$ & $\ln Y=-3.1140+2.4430 \ln D B H$ & [53] \\
\hline & Pinus koraiensis & $5-31$ & $\ln Y=-4.4489+2.8942 \ln D B H$ & [53] \\
\hline & Taxus cuspidata & $2-15$ & $\ln Y=-3.7842+2.4407 \ln D A G$ & [58] \\
\hline
\end{tabular}

$\mathrm{BL}=$ broad-leaved tree, $\mathrm{CT}=$ coniferous tree, $Y=$ carbon storage $(\mathrm{kg}), D B H=$ diameter at breast height $(\mathrm{cm})$, and $D A G=$ diameter at $15 \mathrm{~cm}$ above ground for shrubs $(\mathrm{cm})$.

\section{Appendix 2}

Carbon uptake allometric equation model for urban tree.

\begin{tabular}{|c|c|c|c|c|}
\hline & Species & $\begin{array}{c}\text { Diameter range } \\
(\mathrm{cm})\end{array}$ & Allometric equations model & Reference \\
\hline \multirow{9}{*}{ BL } & \multirow{2}{*}{ Acer palmatum } & $7-27$ & $\begin{array}{c}Y=e(-0.4617+1.8613 \ln D B H) \times 0.0883 \\
\times 1.0202-e(-2.1744+1.7294 \ln D B H) \times 0.4748\end{array}$ & \multirow[t]{2}{*}[50]{} \\
\hline & & $5-20$ & $Y=0.9608+0.1535 \mathrm{DBH}$ & \\
\hline & Chionanthus retusus & $3-11$ & $\ln Y=-2.2695+1.7554 \ln D B H$ & {$[58]$} \\
\hline & Cornus officinalis & $3-15$ & $\ln Y=-3.1622+1.8844 \ln D A G$ & [58] \\
\hline & \multirow[t]{2}{*}{ Ginkgo biloba } & $6-31$ & $\begin{array}{c}Y=e(-2.0430+2.3359 \ln D B H) \times 0.2338 \times 0.5769- \\
e(-4.5072+2.5136 \ln D B H) \times 0.5742\end{array}$ & \multirow[t]{2}{*}[50]{} \\
\hline & & $5-25$ & $\ln Y=-3.6471+1.8287 \ln D B H$ & \\
\hline & Prunus armeniaca & $4-14$ & $\ln Y=-2.8278+1.8824 \ln D B H$ & [58] \\
\hline & Prunus yedoensis & $5-23$ & $\ln Y=-3.0939+1.7702 \ln D B H$ & [52] \\
\hline & Zelkova serrata & $5-28$ & $\ln Y=-2.8177+1.7715 \ln D B H$ & [52] \\
\hline \multirow{6}{*}{$\mathrm{CT}$} & Abies holophylla & $5-19$ & $\ln Y=-3.1386+1.6158 \ln D B H$ & [58] \\
\hline & \multirow[b]{2}{*}{ Pinus densiflora } & $5-25$ & $\ln Y=-2.6720+1.5251 \ln D B H$ & [53] \\
\hline & & $5-29$ & $\begin{array}{c}Y=\mathrm{e}(-0.9896+1.7140 \ln D B H) \times 0.8982 \times 0.8241-e(- \\
4.2318+2.4175 \ln D B H) \times 0.8299 \times(12 / 44)\end{array}$ & [51] \\
\hline & \multirow[b]{2}{*}{ Pinus koraiensis } & $5-31$ & $\ln Y=-4.4881+2.2262 \ln D B H$ & [53] \\
\hline & & $5-33$ & $\begin{array}{c}Y=e(-0.6065+1.6955 \ln D B H) \times 0.7176 \times 0.8657-e(- \\
3.3132+2.1351 \ln D B H) \times 0.8299 \times(12 / 44)\end{array}$ & [51] \\
\hline & Taxus cuspidata & $2-15$ & $\ln Y=-4.7726+1.8554 \ln D A G$ & [58] \\
\hline
\end{tabular}

